\title{
Irritable Bowel Syndrome among Medical Students and Interns in King Faisal University
}

\author{
Wissam Abdullatif Alsuwailm*, Maryam Munahi AL-Qahtani*, Anwar Abdullatif AL-Hulaibi*, \\ Marwah Abdulaziz AL-Hadi*, Wala'a Tawfeeq Busa'ad", Sayed Ibrahim Ali*\#, \\ Somaia Abdelmohsen Shehabeldeen*
}

Collage of Medicine, KFU, Al-Hasa, KSA

Email: "drsamas38@gmail.com

How to cite this paper: Alsuwailm, W.A., AL-Qahtani, M.M., AL-Hulaibi, A.A., AL-Hadi, M.A., Busa'ad, W.T., Ali, S.I. and Shehabeldeen, S.A. (2017) Irritable Bowel Syndrome among Medical Students and Interns in King Faisal University. Open Journal of Preventive Medicine, 7, 235-246. https://doi.org/10.4236/ojpm.2017.711019

Received: October 18, 2017

Accepted: November 26, 2017

Published: November 29, 2017

Copyright $\odot 2017$ by authors and Scientific Research Publishing Inc. This work is licensed under the Creative Commons Attribution International License (CC BY 4.0).

http://creativecommons.org/licenses/by/4.0/

(c) (i) Open Access

\begin{abstract}
Background: One of the most highly prevalent costly gastrointestinal disorders is IBS. It is a consequence of emotional conflicts and stress. So people who are in medical education, they have highest percentage of IBS. Objective: To estimate the prevalence of IBS and its effects on the academic achievement among medical students of KFU, Al-Hasa, Saudi Arabia. Methods: A crosssectional study was carried out among medical students and interns from August 2015 to September 2016 at (KFU) in Al-Hasa, Saudi Arabia. All participants were asked to complete a confidential self-administered questionnaire. Diagnosis of IBS was according to Rome III criteria. Results: 173 medical students completed the survey. The prevalence of IBS was $44.5 \%$, with a high prevalence in females (31.8\%). IBS was present significantly higher among students who experience emotional stress in the past 6-month (25.4\%) and higher among students with a positive family history of IBS. Moreover, IBS was associated with a decrease in the academic performance among medical students $(\mathrm{p}<0.05)$. Conclusion: The study revealed a high percentage of IBS among medical students and interns in KFU. Female gender, having emotional stress in the past 6 months and family history of IBS were the main predictors of IBS. However, the main predictor of IBS was in family history.
\end{abstract}

\section{Keywords}

Irritable Bowel Syndrome, Medical Students, King Faisal University, Saudi Arabia

\section{Introduction}

Irritable bowel syndrome (IBS) is a form of functional gastrointestinal disorder

*All authors have contributed to this article equally. 
and it is one of the most common diagnosis in clinics [1]. Abdominal pain or discomforts with a change in bowel habits only and without any change anatomical or histology in the intestine are main features of IBS [2] [3].

The pathological cause of IBS is unclear, and studies have revealed that there are many biological, psychological, and social factors may play a role like gender, diet, lifestyle, stress, sleep problems, early adverse life events (EALs), and psychiatric disorders [4] [5] [6]. Medical students have many factors that may cause excessive stress which includes high levels of emotional and psychological stress due to heavy study and exams load, increasing fierce competition for jobs, undesirable living, eating habits, and the responsibility of managing patients [3]. All these are showed why there is a rise in prevalence of IBS among medical students [7] [8] [9] [10].

The diagnosis of IBS depends on different diagnostic criteria including Manning criteria, Rome I criteria or Rome II criteria [11]. The most common criteria used for the detection of IBS clinically is Rome III criteria which defines IBS as recurrent abdominal pain or discomfort for at least 3 days/months during last 6 months associated with two or more of the following features: 1) Improvement with defecation. And/or 2) Onset associated with a change in frequency of stool. And/or 3) Onset associated with a change in form (appearance) of stool [2].

The prevalence of IBS differs significantly across the world and mainly depends on the diagnostic criteria used [8]. According to the worldwide prevalence of IBS, it ranges from $5.7 \%$ to $34 \%$ [11]. As reported by various studies in western countries it ranges from $17 \%-22 \%$ with a highly range of prevalence observed in Asian countries i.e. 2.3\% - 34\% [12]. Recently the morbidity of Asian countries is rising year by year [3] [4] [13] and [14].

The burden of IBS is significant enough to contribute to a considerable impairment in quality of life by affecting the person's social and emotional functioning leading to depression, decrease academic achievement and increase rate of absences from schools and work stations [15].

Though IBS is prevalent in Western countries, its prevalence is less in Arab countries, including Kingdom of Saudi Arabia [11]. The data about prevalence and related factors in medical students can improve the symptoms of IBS patients and their quality of life by providing specific recommendations for the treatment of IBS. However, there is no inclusive survey (including diet, prevalence, lifestyle, psychiatric disorders, sleep problems, EALs, and stress) about IBS using Rome III criteria has been carried out on medical students in King Faisal University (KFU) nowadays.

As a result, the association between stress and IBS among medical student has not previously studied in KFU in Al-Hasa. So the aim of this study were to investigate the prevalence and the pattern of lifestyle related risk factors of IBS and its effects on the academic achievement among medical students of KFU medical college.

\section{Methods}

A cross-sectional study was conducted among medical students and interns at King 
Faisal University (KFU) in Al-Hasa, Saudi Arabia during 1/8/2015-25/9/2016.

The study included KFU medical students from the first to the sixth year and interns with the following exclusion criteria: participants with known organic gastrointestinal disorder, individuals with family history of cancer and/or individuals with alarming signs and symptoms like: weight loss, anemia, and bloody stools.

A 384 well-structured questionnaire, was randomly distributed among the medical students and interns, during their regularly scheduled class time, a total of 173 completed the questionnaires.

Prior to data collection, the ethical approval was obtained from the Institutional Review Board research ethical committee in the College of Medicine, KFU and conformed to the ethical standards of the Helsinki declaration. The approval was taken from the administration. In addition, the purpose of the study was explained to the participants and a written and informed consent was obtained. Also, the participant was assured of the confidentiality of the survey and that their names will not be used.

Data collected by using well-structured questionnaire, the proposed questionnaire consisted of 35 questions covering five parts:

- The first part related to Personal and socio-demographic data of the study sample (age, gender, marital status, medical year and so on).

- The second part related to daily lifestyle factors (such as dietary habits, exercise, number of sleeping hours and so on).

- The third part related to Rome III criteria.

- The fourth part related to Red-flag items: there are 7 red-flag items used to identify organic intestinal disease from IBS according to the American Gastroenterological Association. They are drastic weight loss, a history of organic bowel disease, a history of digestive surgery, blood in stool, awakening due to abdominal pain during night, anemia, fever or arthralgia. Participants who have one or more of these red flags were excluded from the study.

- The fifth part related to IBS effects on the academic achievement of the medical student.

- The remaining questions were about the family history of IBS, psychological aspect and health background of medical students and interns.

\section{Statistical Analysis}

Data were analyzed using the statistical software program SPSS version 22 (SPSS Inc., Chicago, IL). Data is presented as mean $\pm \mathrm{SD}$ and Chi-square test was conducted to observe and quantify an association between the categorical outcome and the different variables. The t-test was used to compare group differences for continuous variables. Adjusted odds ratios (ORs) and their 95\% confidence intervals are reported. Statistical significance was defined as a $\mathrm{P}$ value $<0.05$.

\section{Results}

A total of 173 questionnaires were distributed, completed and analyzed with a 
response rate of $100 \%$. The subjects include $102(59 \%)$ female and 71 (41\%) male students. The majority of the students were single (82.7\%) and living with their family $(81.5 \%)$. Regarding lifestyle (63\%) have normal BMI and more than onehalf (57.2\%) practiced physical exercise. Most of the students (86\%) were not on regular medications.

About more than one-third (36.4\%) of students had positive family history of IBS. In the current analysis, Rome III Criteria identified 77 students diagnosed as having IBS; giving an overall IBS prevalence of $44 \%$ among medical students and interns. The females (31.8\%) were found to have a higher prevalence of IBS compared to males (12.7\%) as shown in Figure 1.

Table 1 shows that the females (31.8\%) are significantly prone to develop IBS more than males $(12.7 \%)(\mathrm{p}<0.003)$. IBS is higher among $6^{\text {th }}$ year students but not significant $(\mathrm{P}>0.05)$. Single students found to have a higher rate $(36.4 \%)$ of IBS in comparison to married ones (8.1\%). However, there is no statistical significant difference $(\mathrm{p}>0.05)$. Also, IBS is found to be higher among students living with their families (37\%) in comparison to those living in school dormitories $(1.7 \%)$ or private $(5.8 \%)$ but with no statistical significant difference $(\mathrm{p}>$ $0.05)$.

Table 2 demonstrates that the prevalence of IBS low in students who practiced physical exercise. Thereafter, there is no significant difference $(p>0.05)$. Similarly, the prevalence of IBS higher in students who have normal weight, slept fewer hours per day ( $<8 \mathrm{~h} /$ day), consumed fatty food ( $1-2$ per week) and who drink tea and coffee ( $1-2$ of cups) per day.

It is apparent from Table 3 that students with a positive family history of the disease $(22.5 \%)$, compared to others $(22 \%)(\mathrm{p}<0.05)$ have statistically significant difference in the prevalence of IBS. The rate of IBS was higher among participants who do not have any chronic health problem (37.2\%), compared to others who have chronic health problem (7\%), but this difference is statistically

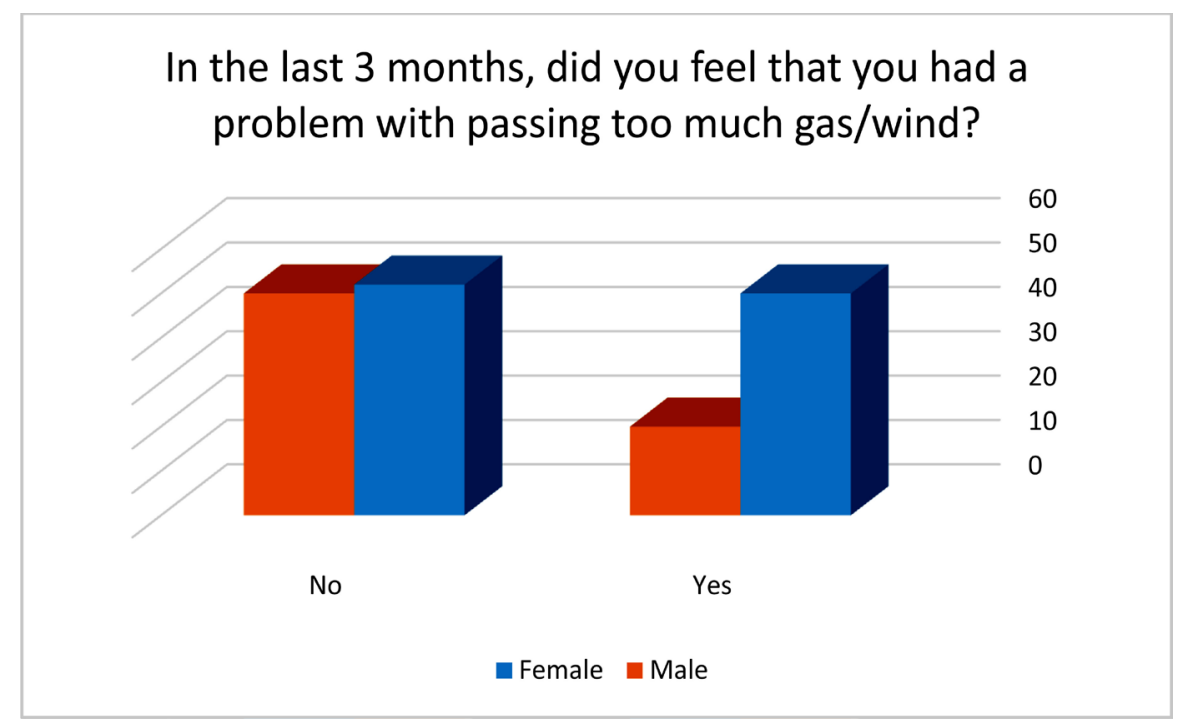

Figure 1. The prevalence of IBS among females compared to males. 
Table 1. Relationship between irritable bowel syndrome and personal, socio-demographic characteristics of medical students and interns in King Faisal University.

\begin{tabular}{|c|c|c|c|c|c|c|c|c|}
\hline \multirow{2}{*}{$\begin{array}{c}\text { Irritable bowel } \\
\text { syndrome variable }\end{array}$} & \multicolumn{2}{|c|}{ IBS } & \multicolumn{2}{|c|}{ NOIBS } & \multirow{2}{*}{$P$} & \multirow{2}{*}{ Chi-square } & \multirow{2}{*}{ OR } & \multirow{2}{*}{$95 \% \mathrm{CI}$} \\
\hline & No. & $\%$ & No. & $\%$ & & & & \\
\hline \multicolumn{9}{|l|}{ Sex: } \\
\hline Female & 55 & $31.80 \%$ & 47 & $27.20 \%$ & \multirow[b]{2}{*}{$0.003^{*}$} & \multirow[b]{2}{*}{8.916} & \multirow[b]{2}{*}{2.61} & \multirow[b]{2}{*}{$(1.38,4.92)$} \\
\hline Male & 22 & $12.70 \%$ & 49 & $28.30 \%$ & & & & \\
\hline \multicolumn{9}{|l|}{ Academic year: } \\
\hline $1^{\text {st }}$ & 7 & $4.10 \%$ & 16 & $9.30 \%$ & \multirow{7}{*}{0.418} & \multirow{7}{*}{6.048} & \multirow{7}{*}{-} & \multirow{7}{*}{-} \\
\hline $2^{\text {nd }}$ & 15 & $8.70 \%$ & 20 & $11.60 \%$ & & & & \\
\hline $3^{\text {rd }}$ & 10 & $5.80 \%$ & 13 & $7.60 \%$ & & & & \\
\hline $4^{\text {th }}$ & 8 & $4.20 \%$ & 9 & $5.20 \%$ & & & & \\
\hline $5^{\text {th }}$ & 12 & $7 \%$ & 6 & $3.50 \%$ & & & & \\
\hline $6^{\text {th }}$ & 19 & $11 \%$ & 26 & $15.10 \%$ & & & & \\
\hline Intern & 6 & $3.50 \%$ & 5 & $2.90 \%$ & & & & \\
\hline \multicolumn{9}{|l|}{ Marital status: } \\
\hline Single & 63 & $36.40 \%$ & 80 & $46.20 \%$ & \multirow{2}{*}{0.794} & \multirow{2}{*}{0.068} & \multirow{2}{*}{0.9} & \multirow{2}{*}{$(0.41,1.98)$} \\
\hline Married & 14 & $8.10 \%$ & 16 & $9.20 \%$ & & & & \\
\hline \multicolumn{9}{|l|}{ Living condition: } \\
\hline With family & 64 & $37 \%$ & 77 & $44.50 \%$ & & & & \\
\hline Private & 10 & $5.80 \%$ & 14 & $8.10 \%$ & 0.869 & 0.282 & - & - \\
\hline School dormitory & 3 & $1.70 \%$ & 5 & $2.90 \%$ & & & & \\
\hline
\end{tabular}

Table 2. Relationship between irritable bowel syndrome and habits of medical students and interns in King Faisal University.

\begin{tabular}{|c|c|c|c|c|c|c|c|c|}
\hline \multirow{2}{*}{$\begin{array}{c}\text { Irritable bowel } \\
\text { syndrome variable }\end{array}$} & \multicolumn{2}{|c|}{ IBS } & \multicolumn{2}{|c|}{ NOIBS } & \multirow{2}{*}{$P$} & \multirow{2}{*}{ Chi-square } & \multirow{2}{*}{ OR } & \multirow{2}{*}{$95 \% \mathrm{CI}$} \\
\hline & No. & $\%$ & No. & $\%$ & & & & \\
\hline \multicolumn{9}{|l|}{ Exercise: } \\
\hline Yes & 14 & 8.1 & 21 & 12.1 & & & & \\
\hline No & 32 & 18.5 & 42 & 24.3 & 0.692 & 0.736 & - & - \\
\hline Sometime & 31 & 17.9 & 33 & 19.1 & & & & \\
\hline \multicolumn{9}{|c|}{ Number of sleeping hours: } \\
\hline$<8$ & 47 & 27.5 & 56 & 32.7 & 0.701 & 0.148 & 1.129 & $(0.61-2.1)$ \\
\hline$\geq 8$ & 29 & 17 & 39 & 22.8 & & & & \\
\hline \multicolumn{9}{|l|}{ Nutritional status (BMI): } \\
\hline Underweight & 11 & 6.4 & 13 & 7.5 & \multirow{4}{*}{0.635} & \multirow{4}{*}{1.711} & \multirow{4}{*}{-} & \multirow{4}{*}{-} \\
\hline Normal & 49 & 28.3 & 60 & 34.7 & & & & \\
\hline Obese & 12 & 6.9 & 20 & 11.6 & & & & \\
\hline Overweight & 5 & 2.9 & 3 & 1.7 & & & & \\
\hline
\end{tabular}




\section{Continued}

Fatty food consumption (average frequency per week):

$\begin{array}{ccccccccc}\text { None } & 1 & 0.6 & 3 & 1.7 & & & \\ <1 & 12 & 6.9 & 14 & 8.1 & & & & - \\ 1-2 & 41 & 23.7 & 52 & 30.1 & & & & \\ >2 & 23 & 13.3 & 27 & 15.6 & & & \end{array}$

Tea or coffee Intake

(2. of cups per day):

$\begin{array}{ccccccccc}\text { None } & 26 & 15 & 39 & 22.5 & & & \\ 1-2 & 39 & 22.5 & 44 & 25.4 & 0.619 & 0.865 & - & - \\ >2 & 12 & 6.9 & 13 & 7.5 & & & \end{array}$

Table 3. Relationship between irritable bowel syndrome and family history, psychological aspect and health background of medical students and interns in King Faisal University.

\begin{tabular}{|c|c|c|c|c|c|c|c|c|}
\hline \multirow{2}{*}{$\begin{array}{c}\text { Irritable bowel } \\
\text { syndrome variable }\end{array}$} & \multicolumn{2}{|c|}{ IBS } & \multicolumn{2}{|c|}{ NOIBS } & \multirow{2}{*}{$P$} & \multirow{2}{*}{ Chi-square } & \multirow{2}{*}{ OR } & \multirow{2}{*}{$95 \% \mathrm{CI}$} \\
\hline & No. & $\%$ & No. & $\%$ & & & & \\
\hline \multicolumn{9}{|l|}{ Family history of IBS } \\
\hline Yes & 39 & 22.5 & 24 & 13.9 & \multirow[b]{2}{*}{0.0001} & \multirow[b]{2}{*}{12.14} & \multirow[b]{2}{*}{3.08} & \multirow[b]{2}{*}{$(1.61,5.86)$} \\
\hline No & 38 & 22 & 72 & 41.6 & & & & \\
\hline \multicolumn{9}{|c|}{ Chronic health problem: } \\
\hline Yes & 12 & 7 & 9 & 5.2 & \multirow{2}{*}{0.202} & \multirow[b]{2}{*}{1.63} & \multirow{2}{*}{1.81} & \multirow[b]{2}{*}{$(0.71,4.6)$} \\
\hline No & 64 & 37.2 & 87 & 50.6 & & & & \\
\hline \multicolumn{9}{|l|}{ Medication use } \\
\hline Yes & 16 & 9.4 & 8 & 4.7 & \multirow[b]{2}{*}{0.015} & \multirow[b]{2}{*}{5.58} & \multirow[b]{2}{*}{2.9} & \multirow[b]{2}{*}{$(1.2,7.2)$} \\
\hline No & 60 & 35.1 & 87 & 50.9 & & & & \\
\hline \multicolumn{9}{|c|}{ NSAIDs Intake (duration); } \\
\hline None & 67 & $38.70 \%$ & 87 & $50.30 \%$ & \multirow{4}{*}{0.57} & \multirow{4}{*}{2.04} & \multirow{4}{*}{-} & \multirow{4}{*}{-} \\
\hline 6 months & 5 & 2.9 & 5 & 2.9 & & & & \\
\hline 1 year & 0 & $0.00 \%$ & 1 & $0.60 \%$ & & & & \\
\hline$>1$ year & 5 & $2.90 \%$ & 3 & $1.70 \%$ & & & & \\
\hline \multicolumn{9}{|c|}{ Living condition: Experience any emotional stress in the past 6-month? } \\
\hline Yes & 44 & 25.4 & 26 & 15 & \multirow[b]{2}{*}{0.0001} & \multirow[b]{2}{*}{16.03} & \multirow[b]{2}{*}{3.6} & \multirow[b]{2}{*}{$(1.9,6.8)$} \\
\hline No & 33 & 19.1 & 70 & 40.5 & & & & \\
\hline
\end{tabular}

non-significant $(\mathrm{p}>0.05)$. The rate of IBS was significantly $(\mathrm{p}<0.05)$ higher among participants who do not use any medication (35.1\%), compared to others (9.4). Students who experience any emotional stress in the past 6-month (25.4\%) have higher significantly difference $(\mathrm{p}<0.05)$ compared to others $(19.1 \%)$.

It is apparent from Table 4 that there is no significant difference $(\mathrm{p}>0.05)$ in the studying hours, absent from lectures more than usual or decreases in atten- 
tion during lectures among students who have IBS and who don't have. However, students who have IBS have statistical significant decrease in studying attention $(\mathrm{p}<0.001)$. Moreover, there is statistical significant change in studying performance $(\mathrm{p}<0.003)$, decrease in duties performance $(\mathrm{p}<0.001)$ and decrease in participation in the classroom and extra-curricular activities $(\mathrm{p}<0.002)$ among students who have IBS.

It is shown in Table 5 that the relationship between the GPA before and after getting IBS symptoms is statistically significant $(p>0.05)$. The GPA of students starts to decrease after they have IBS.

Table 4. Relationship between irritable bowel syndrome and studying performance of medical students and interns in King Faisal University.

\begin{tabular}{|c|c|c|c|c|c|c|c|c|}
\hline \multirow{2}{*}{ Irritable bowel syndrome variable } & \multicolumn{2}{|c|}{ IBS } & \multicolumn{2}{|c|}{ NO IBS } & \multirow{2}{*}{$p$} & \multirow{2}{*}{ Chi-square } & \multirow{2}{*}{ OR } & \multirow{2}{*}{$95 \% \mathrm{CI}$} \\
\hline & $\%$ & NO & $\%$ & NO & & & & \\
\hline \multicolumn{9}{|l|}{ Decreasein studying hours? } \\
\hline Yes & 28 & 16.3 & 26 & 15.1 & \multirow[b]{2}{*}{0.206} & \multirow[b]{2}{*}{1.6} & \multirow[b]{2}{*}{1.52} & \multirow[b]{2}{*}{$(0.8,2.9)$} \\
\hline No & 49 & 28.5 & 69 & 40.1 & & & & \\
\hline \multicolumn{9}{|l|}{ Decrease in studying attention } \\
\hline Yes & 42 & 24.4 & 27 & 15.7 & \multirow{2}{*}{0.001} & \multirow[b]{2}{*}{12.8} & \multirow[b]{2}{*}{3.02} & \multirow{2}{*}{$(1.6,5.7)$} \\
\hline No & 35 & 20.3 & 68 & 39.5 & & & & \\
\hline \multicolumn{9}{|l|}{ Change in studying performance } \\
\hline Yes & 40 & 23.3 & 28 & 16.3 & \multirow[t]{2}{*}{0.003} & \multirow[t]{2}{*}{8.99} & \multirow[t]{2}{*}{2.59} & \multirow[t]{2}{*}{$(1.4,4.8)$} \\
\hline No & 37 & 21.5 & 67 & 39 & & & & \\
\hline
\end{tabular}

Absence from lectures more than usual

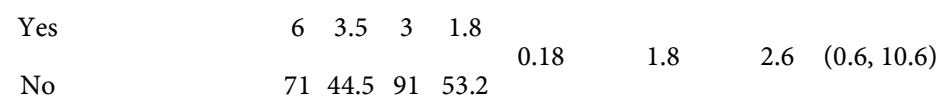

Decrease in attention during lectures

\begin{tabular}{|c|c|c|c|c|c|}
\hline Yes & $\begin{array}{lll}34 & 19.9 & 2\end{array}$ & 14.6 & & & \\
\hline No & $\begin{array}{lll}42 & 24.6 & 7\end{array}$ & 40.9 & & & \\
\hline
\end{tabular}

Decrease in duties performance

$\begin{array}{lllllllll}\text { Yes } & 30 & 17.4 & 15 & 8.7 & & & & \\ \text { No } & 47 & 27.3 & 80 & 46.5 & & & & \end{array}$

Decrease in participation in the classroom and extra-curricular activities

$\begin{array}{llllllllll}\text { Yes } & 27 & 15.7 & 14 & 8.1 & & & & \\ \text { No } & 50 & 29.1 & 81 & 47.1 & & & & & \\ & & & & & & & & & \end{array}$

Table 5. The relationship between irritable bowel syndrome and change in the grade of medical students and interns of King Faisal University.

\begin{tabular}{lcccccc}
\hline & N & Mean & Std. Deviation & T & df & p. value \\
\hline GPA before getting IBS symptoms & 128 & 4.187 & 0.56114 & & & \\
GPA after getting these symptoms & 128 & 4.0665 & 0.64184 & 3.527 & 127 & 0.001 \\
\hline
\end{tabular}




\section{Discussion}

To our knowledge, this was the first comprehensive survey using the Rome III criteria to assess the prevalence of IBS and its effects on the academic achievement of medical students and interns in KFU, AL-Hasa, Saudi Arabia. In Western countries, the range of IBS prevalence was $15 \%$ - 24\% [2].

An international study conducted by Hungin et al., (2003) that the prevalence of IBS was $11.5 \%$ among eight European countries [16]. This study states a higher prevalence of IBS among medical students and interns (44\%). The difference in IBS prevalence among different countries is due to different diagnostic criteria used, the cultural and dietary habits in various countries. Similar to that in previous studies, IBS prevalence in females was significantly higher than in males in our study. A study of Yan-Mei Tan et al. (2003) illustrates that IBS was diagnosed more commonly in females than males, among Malaysian medical students [17]. Shen et al. (2009) found that, Chinese university female students had a higher prevalence of IBS (16.8\%) than male students (14.5\%) [11].

Many studies have shown that the main reason behind the difference in prevalence of IBS regarding the gender is uncertain. Naeem, et al. (2012) explained that, the reasons contribute to the difference in the prevalence of IBS in both sex include sociocultural properties and health seeking behavior or the true biological differences [4]. Other causes of higher IBS prevalence among females may be due to the effect of the estrogen sex hormone on influencing the regulatory mechanisms of the brain-gut axis and also the gender differences in response to stress which is found to be higher in females [18]. Moreover, women are more likely to have mental problems and sleep disorders, which may be related to the high prevalence of IBS. Finally, a gender-based approach must be considered in clinical practice.

This research revealed that, the sixth year students have a higher prevalence of IBS according to the age and the academic year. The reason behind this might be due to potential effort from the study and overwork during clinical years and internship. One study by Chu et al. (2012) reported that, the lower grade medical students had lower risk for functional bowel disorders than higher-grade undergraduates [19]. Moreover, a study from Ontario, Canada, showed that there were no significant differences of the prevalence of IBS between pre-clinical and clerkship students [20].

Mansour et al. (2011) showed that, students living far away from their families had more risk to get IBS compared to others [21]. However, this study was contrasted to our result. This study showed that a higher prevalence of IBS found in students living with their families had compared to those living in school dormitories or private.

Concerning the physical exercise, nowadays many students are too busy to do physical exercises. This study showed that IBS prevalence was higher among students who did not practice physical exercise compared to others. Moreover, some students who have IBS are restrained in their desire to do physical exercise, 
perhaps due to the chronic abdominal pain or discomfort. These results are similar to a study by Basandra et al. (2014) which showed a significant association between IBS prevalence and inadequate physical activities by Indian medical students [22]. Similarly, a study by Dong et al. (2010) revealed that low exercise levels indicate a high risk of IBS among Chinese university students [2]. It has been approved that, stress can be relieved by physical activity; consequently, IBS patients who did not exercise are less able to adapt with a stressful factor in their lives. Moreover, studying in the university being itself an additional stressor exacerbating IBS symptoms.

In this study, it has been shown that student who sleep less hours per day $(<8$ $\mathrm{h} /$ day) are prone to develop IBS compared to others. The same result was found in a study done by Al-Turki et al. (2011) in which insomnia was higher among students who suffer from IBS [23]. Another study from China found that 34.3\% of the middle school students had sleep problems, and poor sleep was independently associated with IBS [24]. It has been demonstrated that poor sleep is a dangerous stress factor, which can seriously influence the cognition, emotion, somatic reaction, and gastrointestinal function [1]. Furthermore, disruption of normal biological rhythm may lead to a change in visceral motility and sensitivity, thereby altering the colonic physiological function of the gut [1].

Our results showed that, those who consumed fatty food (1 - 2 per week) and drink tea and/or coffee ( 1 - 2 of cups) per day had a higher rate of IBS compared to others who didn't. However, the association between the intake of different type of food and the prevalence of IBS is not statistically significant. Our findings are found to be similar among medical students and interns of King Abdulaziz University in Jeddah. Moreover, they are in agreement with Korean medical students [15] [3]. In contrast, Basandra et al. (2014) found that there are significant associations between IBS and the consumption of fatty food among medical students from Northern India [22].

The students with a family history of IBS had significantly higher rates of this disease compared to others $(\mathrm{p}<0.05)$. This agrees with the results of a family-based case-control research conducted in the United States, which revealed that family history of IBS is a known predictor of IBS [25]. Similarly, another familial aggregation of IBS cases was observed in other western countries [26]. It was found that there is an increased IBS risk among the first, second, and third-degree relatives from a Swedish population [14].

Regarding the academic performance, the present study revealed that IBS is associated with a decrease in the academic performance of medical students. The prevalence of IBS was higher among sixth year students. This attributes to high clinical load, study, and stressors, which associated with decrease performance. These results are similar to those obtained by Ibrahim et al. (2013) who reported that, the students with low grade had a higher prevalence of IBS [14]. However, one study done by Al-Ghamdi et al. (2015) concluded that, IBS is not significantly associated with decrease in the academic performance of male medical 
students [27].

\section{Conclusion}

Medical students are at high risk to get IBS. Our study showed that the prevalence of IBS is higher among medical students and interns at King Faisal University (KFU) in Al-Hasa (44.5\%). A substantial amount of anxiety and stress play a factor with high prevalence of IBS. The main predictors of IBS in this study were being female gender, presence of emotional stress in the past 6 months and family history of IBS. In addition, this study concluded that IBS is significantly associated with decrease in the academic performance of medical students. Despite its prevalence, awareness needs strongly to be raised among students about IBS with stress management courses and reducing the risk factors to enable the students to cope with stressors and subsequently to lessen the undesirable outcomes of the disease.

\section{References}

[1] Liu, Y., Liu. L., Yang, Y., He, Y., Zhang, Y., et al. (2014) A School-Based Study of Irritable Bowel Syndrome in Medical Students in Beijing, China: Prevalence and Some Related Factors. Gastroenterology Research and Practice, Article ID: 124261.

[2] Dong, Y.Y., Zuo, X.L., Li, C.Q., Yu, Y.B., Zhao, Q.J. and Li, Y.Q. (2010) Prevalence of Irritable Bowel Syndrome in Chinese College and University Students Assessed Using Rome III Criteria. World Journal of Gastroenterology, 16, 4221-4226. https://doi.org/10.3748/wjg.v16.i33.4221

[3] Jung, H.J., Park, M.I., Moon, W., Park, S.J., Kim, H.H., Noh, E.J., et al. (2011) Are Food Constituents Relevant to the Irritable Bowel Syndrome in Young Adults? - A Rome III Based Prevalence Study of the Korean Medical Students. Journal of Neurogastroenterology and Motility, 17, 294-299. https://doi.org/10.5056/jnm.2011.17.3.294

[4] Naeem, S., Siddiqui, E., Kazi, A., Memon, A., Khan, S. and Ahmed, B. (2012) Prevalence and Factors Associated with Irritable Bowel Syndrome among Medical Students of Karachi, Pakistan: A Cross-Sectional Study. BMC Research Notes, 2012, 5.

[5] Anbardan, S., Daryani, N., Fereshtehnejad, S., Vakili, S., Keramati, M. and Ajdarkosh, H. (2012) Gender Role in Irritable Bowel Syndrome: A Comparison of Irritable Bowel Syndrome Module (ROME III) between Male and Female Patients. Journal of Neurogastroenterology and Motility, 18, 70-77. https://doi.org/10.5056/jnm.2012.18.1.70

[6] Chang, L. (2011) The Role of Stress on Physiologic Responses and Clinical Symptoms in Irritable Bowel Syndrome. Gastroenterology, 140, 761-765. https://doi.org/10.1053/j.gastro.2011.01.032

[7] Ghanaei, F., Fallah, M.S., Heidarzadeh, A., Jafarshad, R. and Joukar, F. (2011) Rezvan-Ghasemipour Prevalence and Characteristics of Irritable Bowel Syndrome (IBS) amongst Medical Students of Gilan Northern Province of Iran, MEJDD, 1, 100-105.

[8] Abdulmajeed, A., Rabab, M.A., Sliem, H.A. and Hebatallah, N.E. (2011) Pattern of Irritable Bowel Syndrome and Its Impact on Quality of Life in Primary Health Care Center Attendees, Suez Governorate, Egypt. Pan African Medical Journal, 9, 5.

[9] Okami, Y., Kato, T., Nin, G., Harada, K., Aoi, W., Wada, S., Higashi, A., Okuyama, Y., Takakuwa, S., Ichikawa, H., Kanazawa, M. and Fukudo, S. (2011) Lifestyle and 
Psychological Factors Related to Irritable Bowel Syndrome in Nursing and Medical School Students. Journal of Gastroenterology, 46, 1403-1410. https://doi.org/10.1007/s00535-011-0454-2

[10] Jimenez, C., Navia-Osorio, P.M. and Diaz, C.V. (2010) Stress and Health in Novice and Experienced Nursing Students. Journal of Advanced Nursing, 66, 442-455. https://doi.org/10.1111/j.1365-2648.2009.05183.x

[11] Shen, L., Kong, H. and Hou, X. (2009) Prevalence of Irritable Bowel Syndrome and Its Relationship with Psychological Stress Status in Chinese University Students. Journal of Gastroenterology and Hepatology, 24, 1885-1890. https://doi.org/10.1111/j.1440-1746.2009.05943.x

[12] Talley, N., Zinsmeister, A., Van Dyke, C. and Melton, L. (1991) Epidemiology of Colonic Symptoms and the Irritable Bowel Syndrome. Gastroenterology, 101, 927. https://doi.org/10.1016/0016-5085(91)90717-Y

[13] Gulewitsch, M., Enck, P., Schwille-Kiuntke, J., Weimer, K. and Schlarb, A. (2013) Mental Strain and Chronic Stress among University Students with Symptoms of Irritable Bowel Syndrome. Gastroenterology Research and Practice, 8, Article Title: 206574.

[14] Ibrahim, N.K.R., Battarjee, W.F. and Almehmadi, S.A. (2013) Prevalence and Predictors of Irritable Bowel Syndrome among Medical Students and Interns in King Abdulaziz University, Jeddah. The Libyan Journal of Medicine, 8, 21287. https://doi.org/10.3402/ljm.v8i0.21287

[15] Nellesen, D., Yee, K., Chawla, A., Lewis, B.E. and Carson, R.T. (2013) A Systematic Review of the Economic and Humanistic Burden of Illness in Irritable Bowel Syndrome and Chronic Constipation. Journal of Managed Care Pharmacy, 19, 755-764. https://doi.org/10.18553/jmcp.2013.19.9.755

[16] Hungin, A.P., Whorwell, P.J., Tack, J. and Mearin, F. (2003) The Prevalence, Patterns and Impact of Irritable Bowel Syndrome: An International Survey of 40,000 Subjects. Alimentary Pharmacology \& Therapeutics, 17, 643-650. https://doi.org/10.1046/j.1365-2036.2003.01456.x

[17] Tan, Y., Goh, K., Muhidayah, R., Ooi, C. and Salem, O. (2003) Prevalence Irritable Bowel Syndrome in Young Adult Malaysians: A Survey among Medical Students. Journal of Gastroenterology and Hepatology, 18, 1412-1416. https://doi.org/10.1046/j.1440-1746.2003.03212.x

[18] Mulak, A., Tache, Y. and Larauche, M. (2014) Sex Hormones in the Modulation of Irritable Bowel Syndrome. World Journal of Gastroenterology, 20, 2433-2448. https://doi.org/10.3748/wjg.v20.i10.2433

[19] Chu, L., Zhou, H., Lü, B., Li, M. and Chen, M.Y. (2012) An Epidemiological Study of Functional Bowel Disorders in Zhejiang College Students and Its Relationship with Psychological Factors. Chinese Journal of Internal Medicine, 51, 429-432.

[20] Wells, M., Roth, L., McWilliam, M., Thompson, K. and Chande, N. (2012) A Cross-Sectional Study of the Association between Overnight Call and Irritable Bowel Syndrome in Medical Students. Canadian Journal of Gastroenterology, 26, 281-284. https://doi.org/10.1155/2012/865915

[21] Mansour, F., Fallah, M.S., Heidarzadeh, A., Jafarshad, R., Joukar, F. and Rezvan, G. (2011) Prevalence and Characteristics of Irritable Bowel Syndrome (IBS) amongst Medical Students of Gilan Northern Province of Iran. MEJDD, 1, 100-105.

[22] Basandra, S. and Bajaj, D. (2014) Epidemiology of Dyspepsia and Irritable Bowel Syndrome (IBS) in Medical Students of Northern India. Journal of Clinical and Diagnostic Research, 8, JC13-JC16. 
[23] Al-Turki, Y., Aljulifi, Y.A., Al Murayshid, A., Al Omaish, H.R., Al Daghiri, K.S. and Al Seleemi, A.Y. (2011) Prevalence of Irritable Bowel Syndrome among Students in King Saud University, Riyadh, Saudi Arabia. World Family Medicine Journal, 9, 17-20.

[24] Zhou, H.Q., Yao, M., Chen, G.Y., Ding, X.D., Chen, Y.P. and Li, D.G. (2012) Functional Gastrointestinal Disorders among Adolescents with Poor Sleep: A School-Based Study in Shanghai, China. Sleep Breath, 16, 1211-1218. https://doi.org/10.1007/s11325-011-0635-5

[25] Saito, Y.A., Petersen, G.M., Larson, J.J., Atkinson, E.J., Fridley, B.L. and de Andrade, M. (2010) Familial Aggregation of Irritable Bowel Syndrome: A Family Case-Control Study. The American Journal of Gastroenterology, 105, 833-841. https://doi.org/10.1038/ajg.2010.116

[26] Heitkemper, M.M., Kohen, R., Jun, S.E. and Jarrett, M.E. (2011) Genetics and Gastrointestinal Symptoms. Annual Review of Nursing Research, 29, 261-280. https://doi.org/10.1891/0739-6686.29.261

[27] Al-Ghamdi, S., AlOsamey, F., AlHamdan, A., binkhalaf, A., Alnujaydi, A., Turkistani, A., AlRasheed, A., AlShamrani, S., AlQuaydheb, A., Ofaysan, M., AlQuraini, B., Jupier, S. and Arneja, C. (2015) A Study of Impact and Prevalence of Irritable Bowel Syndrome among Medical Students. International Journal of Medicine and Medical Sciences, 7, 139-147. 